\title{
Response to Delayed Fluid Therapy in Crush Syndrome
}

\author{
Cüneyt Ensaria Omaç Tüfekçioglub ${ }^{b}$ Deniz Aylia Tülin Gümüsc \\ Seval Izdesc Sacit Turanlid \\ aNephrology and Dialysis Unit; Departments of ${ }^{b}$ Cardiology, ${ }^{c}$ Anesthesiology, and d Traumatology, \\ Emergency Hospital, Ankara, Turkey
}

\author{
Key Words \\ Crush syndrome - Acute renal failure · Fluid therapy · \\ Dialysis
}

\begin{abstract}
Background: Although early treatment is valuable in the prognosis of crush syndrome, the diagnosis and treatment of many victims are inevitably delayed in major disasters. Patients and Methods: Among the 38 victims of the Marmara earthquake with crush injury, 27 were diagnosed as crush syndrome on the basis of findings of acute renal failure. Intensive intravenous fluid treatment was started in all patients on admission. Of these 27 patients, 10 required dialysis treatment while 17 did not. The laboratory data on admission were evaluated and compared between the two groups. Results: The mean admission time of 27 patients was $46.5 \pm$ (SE) $3.08 \mathrm{~h}$. There was no significant difference between the dialysis and the nondialysis groups with regard to patient's age, trapped time or admission time. A significantly higher number of patients had crush injury in more than one extremity in the dialysis group. The dialysis group had significantly lower systolic blood pressure, central venous pressure but a higher heart rate together with higher levels of serum urea nitrogen, creatinine, creatinine kinase, C-reactive protein, fibrinogen on admission com-
\end{abstract}

pared to the nondialysis group. Conclusion: Our results suggest that even delayed application of aggressive specific fluid treatment under close monitoring may prevent the development of established acute renal failure.

Copyright $\odot 2002$ S. Karger AG, Basel

\section{Introduction}

It is well known that rhabdomyolysis occurring in crush injury $(\mathrm{CI})$ can present with various systemic manifestations such as electrolyte and mineral imbalance, hypovolemia, myoglobinuria and acute renal failure (ARF) [1-3]. This clinical condition, known as crush syndrome (CS), is commonly encountered after earthquakes, and in various other disasters [4]. Early extrication and administration of intravenous fluid treatment are crucially important in preventing kidney failure in patients with CI [1-3, 5]. However, difficulties in communication and transportation in the wake of disasters often interfere with early diagnostic and therapeutic interventions [6-8].

On August 17, 1999, the Marmara, Turkey, earthquake occurred in a highly populated area in the very early hours of the morning and caused over 17,000 deaths while more than 40,000 were injured. The literature concerning medical problems of the victims of major earthquakes and reports presenting previous experiences of the

\section{KARGER \\ Fax + 41613061234 \\ E-Mail karger@karger.ch \\ www.karger.com

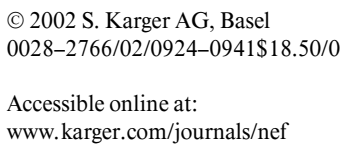

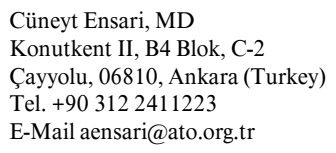




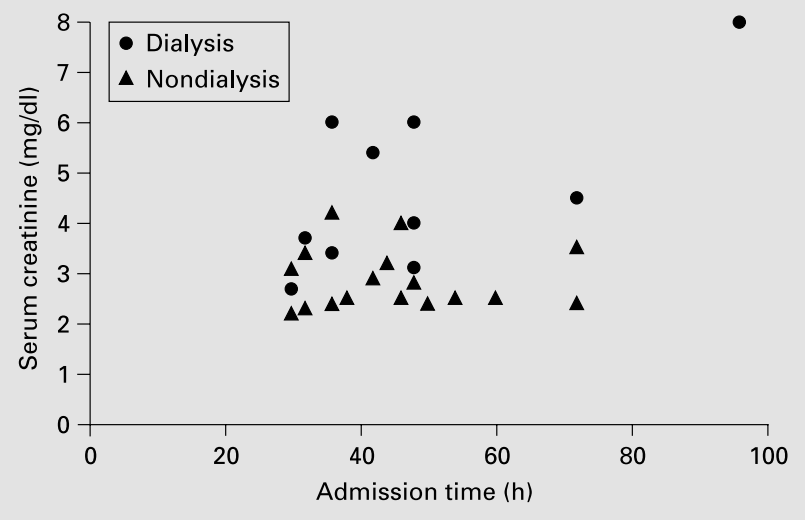

Fig. 1. Admission serum creatinine values of the two patient groups $(\mathrm{p}=0.002)$.

investigators have helped us enormously in dealing with our patients. Since some parts of the world like Turkey carry a high risk of major quakes, we believe that every study documenting data of this disaster may help the medical teams in their future tasks. We therefore decided to present the data on the victims of the Marmara earthquake suffering from CS transported to our hospital which is located approximately $300 \mathrm{~km}$ away from the region and also to discuss the effects of delayed fluid therapy on the prognosis of CS.

\section{Patients and Methods}

Among the 174 victims admitted to our hospital, 38 were diagnosed as CI on the basis of the presence of swollen limbs with a history of limb compression. Of these, 27 patients presenting with myoglobinuria, oligo-anuria (urine output $<20 \mathrm{ml} / \mathrm{h}$ ), high serum urea nitrogen $(>40 \mathrm{mg} / \mathrm{dl})$ and creatinine $(>2 \mathrm{mg} / \mathrm{dl})$ levels were considered as ARF and a diagnosis of CS was made. Under close monitoring, the patients were given intravenous fluid, mannitol and diuretics together with alkalization to maintain urinary $\mathrm{pH}$ above 6.5 , as suggested in the literature $[1-3,5]$. After this regimen sufficient diuresis was restored in $17(63 \%)$ without any need for dialysis treatment while $10(37 \%)$ patients required dialysis treatment. Clinical data were assessed from patients' hospital files. The clinical and laboratory admission values were noted. The differences between the patients who required dialysis therapy and those who did not were analyzed in terms of clinical and laboratory parameters comprising age of the patient, time spent under collapsing buildings (trapped time), time spent between the event and the beginning of specific treatment (admission time), site and extent of injury, systolic blood pressure (SBP), heart rate (HR), central venous pressure (CVP), serum urea nitrogen
Table 1. Clinical and laboratory admission values of the patients (mean $\pm \mathrm{SE})$

\begin{tabular}{lccl}
\hline Parameters & $\begin{array}{l}\text { Dialysis } \\
\text { group } \\
(\mathrm{n}=10)\end{array}$ & $\begin{array}{l}\text { Nondialysis } \\
\text { group } \\
(\mathrm{n}=17)\end{array}$ & $\begin{array}{l}\mathrm{p} \\
\text { value }\end{array}$ \\
\hline Age, years & $30 \pm 2.93$ & $29.2 \pm 2.99$ & $\mathrm{NS}$ \\
Trapped time, h & $13.6 \pm 2.16$ & $11.53 \pm 1.31$ & $\mathrm{NS}$ \\
Admission time, $\mathrm{h}$ & $48.8 \pm 6.4$ & $45.1 \pm 3.2$ & $\mathrm{NS}$ \\
$\mathrm{CI}>$ one extremity & $8(80 \%)$ & $5(29 \%)$ & 0.018 \\
$\mathrm{SBP}, \mathrm{mm} \mathrm{Hg}$ & $75 \pm 7.01$ & $98.8 \pm 5.67$ & 0.023 \\
$\mathrm{HR}, \mathrm{bpm}$ & $116.7 \pm 4.28$ & $102.2 \pm 2.59$ & 0.011 \\
$\mathrm{CVP}, \mathrm{cm} \mathrm{H}_{2} \mathrm{O}$ & $2.55 \pm 0.44$ & $4.8 \pm 0.50$ & 0.006 \\
$\mathrm{BUN}, \mathrm{mg} / \mathrm{dl}$ & $86.3 \pm 5.23$ & $62.8 \pm 3.98$ & 0.002 \\
Creatinine, mg/dl & $4.74 \pm 0.55$ & $2.87 \pm 0.14$ & 0.002 \\
Potassium, mmol/1 & $5.94 \pm 0.46$ & $5.33 \pm 0.21$ & $\mathrm{NS}$ \\
Phosphorus, mg/dl & $5.6 \pm 0.58$ & $4.48 \pm 0.34$ & $\mathrm{NS}$ \\
CK, U/l & $39,507 \pm 7,881$ & $17,810 \pm 2,769$ & 0.006 \\
CRP, mg/dl & $12.3 \pm 2.0$ & $4.6 \pm 1.2$ & 0.002 \\
Fibrinogen, mg/dl & $700 \pm 137$ & $364 \pm 47$ & 0.02 \\
Fasciotomy & $7(70 \%)$ & $10(59 \%)$ & $\mathrm{NS}$ \\
\hline
\end{tabular}

$\mathrm{NS}=$ Not significant $\mathrm{CI}=$ crush injury $; \mathrm{SBP}=$ systolic blood pressure; $\mathrm{HR}=$ heart rate; $\mathrm{CVP}=$ central venous pressure $\mathrm{BUN}=$ blood urea nitrogen; $\mathrm{CK}=$ creatinine kinase; $\mathrm{CRP}=\mathrm{C}$-reactive protein.

(BUN), and serum creatinine, potassium (K), phosphorus (P), creatinine kinase (CK), C-reactive protein (CRP), fibrinogen levels and number of fasciotomies performed.

The results are presented as mean values \pm SE for each patient group and Fisher's exact and Mann-Whitney U tests were performed for statistical analysis. $\mathrm{p}<0.05$ was considered significant.

\section{Results}

Data on our patients' clinical and laboratory investigations are presented in table 1 . The mean age of these 27 patients ( 15 male, 12 female) was $29.5 \pm$ (SE) 2.13 years ranging between 12 and 51 years. There was no difference between the ages of patients who needed dialysis treatment and those who did not. The mean admission time of the 27 patients with $\mathrm{CS}$ was $46.5 \pm 3.08 \mathrm{~h}$ ranging between 30 and $96 \mathrm{~h}$. No significant difference was observed between the two groups of patients with regard to either trapped times or their admission times. All 27 patients had CI in at least one lower limb, while 13 $(48.15 \%)$ showed injury in more than one extremity. A significantly higher number of patients had $\mathrm{CI}$ in more than one extremity in the dialysis group ( 8 of $10 ; 80 \%$ ) compared to the nondialysis group (5 of $17 ; 29 \%$ ). The 
dialysis group had significantly low SBP and CVP with a high heart rate at the time of admission. Significantly higher levels of serum creatinine (fig. 1), BUN, CK, CRP, and fibrinogen were found in the dialysis group when compared to the nondialysis group. No such difference was found between the two groups with regard to serum $\mathrm{K}$ and $\mathrm{P}$ levels. There was no significant difference between the two groups with respect to the number of fasciotomies performed. Dialysis treatment was continued depending on the clinical and biochemical parameters of the patients in the dialysis group. Seven of these and 4 of the nondialysis patients were critically ill requiring intensive follow-up and were transferred to tertiary centers prepared for earthquake victims. In 3 weeks time dialysis treatment was stopped after recovery in renal function in the remaining 3 patients.

\section{Discussion}

It has clearly been shown that the time interval between injury and treatment is very important and that the development of ARF can be prevented even in patients with massive rhabdomyolysis when intense fluid treatment is commenced soon after the injury [1-3, 5]. However, in huge disasters such as the Marmara earthquake, delay in rescue and specific treatment becomes inevitable for most of the victims [6-8]. For similar reasons, none of the suggested aggressive treatment modalities had been given to our patients immediately after the event until their admission to our hospital. Thus, we believe that delayed treatment facilitated the development of ARF superimposed on CI in our patients. However, though delayed, the administration of intensive intravenous fluid, mannitol, alkalization, diuretics and close followup, restored diuresis in some of our patients without any need for dialysis. These patients seemed to be less hypovolemic than those on dialysis treatment when evaluated by heart rate, SBP and CVP on admission. They also had lower serum BUN, creatinine and $\mathrm{CK}$ values compared to the dialysis group at the time of admission. Despite the presence of myoglobinuria, oliguria, and azotemia, it seems reasonable to believe that established ARF has not developed in our patients who responded well to intensive fluid therapy without any requirement for dialysis treatment. It may, thus, be more appropriate to define the status of these patients as transitory azotemia $[1,9]$. Some studies $[10,11]$ have similarly shown that when such fluid therapy has been delayed but still applied intensively, the findings of ARF have disappeared without a need for dialysis treatment. In contrast to these observations, Oda et al. [12] have reported several cases with no response to such treatment at all. However, admission serum creatinine values of their patients and time between extrication and treatment seem to be higher than those of our patients.

In conclusion, it seems reasonable to suggest that even delayed application of intensive specific intravenous fluid treatment under close monitoring may prevent the development of established ARF, thereby decreasing the need for dialysis treatment in patients with CS.

\section{References}

1 Better OS, Stein JH: Early management of shock and prophylaxis of acute renal failure in traumatic rhabdomyolysis. N Engl J Med 1990; 372:825-829.

2 Michaelson M: Crush injury and crush syndrome. World J Surg 1992;16:899-903.

3 Abassi ZA, Hoffman A, Better OS: Acute renal failure complicating muscle crush injury. Semin Nephrol 1998;18:558-565.

4 Better OS: Acute renal failure in casualties of mass disasters. Kidney Int 1993;43(suppl 41):S235-S236.

5 Ron D, Taitelman U, Michaelson M, BarJoseph G, Bursztein S, Better OS: Prevention of acute renal failure in traumatic rhabdomyolysis. Arch Intern Med 1984;144:277-280.
6 Shimazu T, Yoshioka T, Nakata Y, Ishikawa K, Mizushima Y, Morimoto F, Kishi M, Takaoka M, Tanaka H, Iwai A, Hiraide A: Fluid resuscitation and systemic complications in Crush Syndrome: 14 Hanshin-Awaji earthquake patients. J Trauma 1997;42:641-646.

7 Guha-Sapir D, Carballo M: Disaster in Turkey: Lessons for health preparedness. Lancet 1999; 354:1649.

8 Sever MS, Erek E, Vanholder R, Akoglu E, Yavuz M, Ergin H, Tekce M, Korular D, Tulbek MY, Keven K, van Vlem B, Lameire N: The Marmara earthquake: Epidemiological analysis of the victims with nephrological problems. Kidney Int 2001;60:1114-1123.

9 Better OS: The crush syndrome revisited (1940-1990). Nephron 1990;55:97-103.
10 Kazancioglu R, Korular D, Sever MS, Türkmen A, Aysuna N, Kayacan SM, Tahin S, Yil$\operatorname{diz}$ A, Bozfakioglu S, Ark E: The outcome of patients presenting with crush syndrome after the Marmara earthquake. Int J Artificial Organs 2001;24:17-21.

11 Iskit SH, Alpay H, Tugtepe H, Özdemir C, Ayyildiz SH, Özel K, Bayramiçli M, Tetik C, Dagli TE: Analysis of 33 pediatric trauma victims in the 1999 Marmara, Turkey earthquake. J Pediatr Surg 2001;36:368-372.

12 Oda Y, Shindoh M, Yukioka H, Nishi S, Fujimori M, Asada A: Crush syndrome sustained in the 1995 Kobe, Japan earthquake: Treatment and outcome. Ann Emergency Med 1997; 30:507-512. 